\title{
Clinical Outcomes after Intravascular Ultrasound Assessment of Coronary Intermediate Lesions
}

\author{
Houissa Khalil ${ }^{1-3}$, Lahidheb Dhaker ${ }^{2}$, Hajlaoui Nadhem², Ben Mansor Nizar ${ }^{2}$, Gommidh Mehdi' ${ }^{2}$, Hagui \\ Abdedayem $^{2}$, Carlier Stéphane ${ }^{1,3 *}$, Fehri Wafa ${ }^{2}$ and Haouala Habib ${ }^{2}$ \\ ${ }^{1}$ Department of Cardiology, Faculty of medicine and pharmacy, The University of Mons, Belgium \\ ${ }^{2}$ Department of Cardiology, Military Hospital of Tunis, Tunisia \\ ${ }^{3}$ Department of Cardiology, CHU Ambroise Paré Mons, Belgium
}

Submission: December 14, 2016; Published: January 04, 2017

*Corresponding author: Stéphane Carlier, Université de Mons, Faculté de Médecine et de Pharmacie, Service de Cardiologie, Avenue Maistriau, 25, 7000 Mons, Tel: +32(0)65 3733 81; Fax: +32(0)65 3733 79; Email: Stephane.CARLIER@umons.ac.be

Abstract

Purpose: Coronary angiography has limitations in the assessment of intermediate coronary lesions (ICL). Intravascular ultrasound (IVUS) can evaluate more accurately the severity of a lesion to guide the therapeutic strategy. This study sought to evaluate long-term clinical outcomes after IVUS-guided coronary revascularization of ICL lesions in patients from the Western Mediterranean region of coastal North Africa (Maghreb) in whom IVUS severity criteria have not been validated.

Methods: We conducted a prospective monocentric study including 113 patients with angiographic ICL evaluated by IVUS. Minimal lumen area (MLA) cut-offs value to perform revascularization were $6 \mathrm{~mm}^{2}$ for the left main coronary artery (LMCA) and $4 \mathrm{~mm}^{2}$ for non- LMCA lesions. The primary outcome was defined as a composite of major adverse cardiac events (MACE) including death, myocardial infarction (MI), and target lesion revascularization (TLR) at 12 months.

Results: Mean age was 59,5 $\pm 12,0$ years, $79 \%$ were men. Multi-vessel disease was present in $65.5 \%$ of our patients, of whom 36 patients had LMCA disease. We analysed 146 arteries with 178 lesions. Revascularization was deferred for $\mathrm{n}=46$ (40.7\%) patients after IVUS evaluation. After a mean follow-up of $20 \pm 10$ months, we observed no significant differences between the revascularized patients and the patients with a deferred revascularization strategy in terms of mortality $(1.5 \%$ and $2.2 \%$ respectively, $\mathrm{p}=0.7)$, and a favourable safety trend for 12 -month rate of MACE ( $10.6 \%$ and $2.2 \%$ respectively, $\mathrm{p}=0.165)$, MI ( $4.5 \%$ and $2.2 \%, \mathrm{p}=0.44)$ and TLR $(10.7 \%$ and $2.2 \%, \mathrm{p}=0.23)$.

Conclusion: We demonstrate that previously validated IVUS criteria to defer revascularization of angiographically ICL can be safely applied to Maghrebi patients.

Keywords: Intravascular ultrasound; Coronary artery disease

Abbreviations: ICL: Intermediate Coronary Lesions; IVUS: Intra Vascular Ultra Sound; FFR: Fractional Flow Reserve; MACE: Major Adverse Cardiac Events; MI: Myocardial Infarction; TLR: Target Lesion Revascularization; LMCA: Left Main Coronary Artery; LAD: Left Anterior Descending Artery; MLA: Minimal Lumen Area; PB: Plaque Burden; LL: Lesion Length; RD: Reference Diameter; PCI: Percutaneous Coronary Intervention; CABG: Coronary Artery Bypass Graft; NSTEMI: Non ST Elevation Myocardial Infarction; STEMI: ST Elevation Myocardial Infarction

\section{Introduction}

Clinical decision making and the management of intermediate coronary lesions (ICL) continues to be a therapeutic dilemma for cardiologists. The limitations of coronary angiography for the evaluation of such lesions are well recognized since 20 years [1], and adjunctive diagnostic techniques have been developed. Intravascular ultrasound (IVUS) offers the possibility to base decisions not only on lumeno grams but also on true lumen and vessel size and plaque accumulation in the coronary wall. The IVUS criteria reported in the literature defining a functional significant coronary stenosis have been recently reassessed and compared with the fractional flow reserve (FFR) derived from intracoronary pressure measurements. The princeps criteria of a significant stenosis based on a lumen area less than $4 \mathrm{~mm}^{2}$ has 
been challenged by numerous investigators proposing down to $2.1 \mathrm{~mm}^{2}[2-16]$.

However, many of these studies were only reporting a head to head comparison with a FFR cut off of 0.75 or 0.8 without outcome data, while a recent prospective study of nearly 700 patients demonstrated that ICL with a lumen area $<4 \mathrm{~mm}^{2}$ were associated with three more times major adverse cardiovascular events [17]. The aim of this study was to evaluate long-term clinical outcomes in patients from Western Mediterranean region of coastal North Africa (Maghreb) where IVUS studies so far have not been conducted and reported. In these patients, Percutaneous coronary intervention of angiographically ICL was decided on the basis of the IVUS findings using criteria reported in Western population and Asia but so far not prospectively assess in this region of North Africa characterized by a high incidence of diabetes mellitus and hypertension $[18,19]$.

\section{Methods}

Study population: Between October 2010 and December 2013, we conducted a prospective monocentric study including 113 patients with angiographically ICL who underwent IVUS assessment to decide whether to perform or not revascularization. Patients with acute myocardial infarction, significant distal lesions, those in whom the IVUS-imaging catheter failed to cross the lesion due to severe stenosis or tortuosity and small vessels (reference diameter $<2.5 \mathrm{~mm}$ ) were excluded. The primary outcome was defined as a composite of major adverse cardiac events (MACE) including death, myocardial infarction (MI), and target lesion revascularization (TLR) at 12 months.

Angiographic analysis: Coronary angiography was performed with GE Innova ${ }^{\circledR} 2000$ and Innova ${ }^{\circledR} 2100$ IQ interventional cardiology systems. Visual estimation of lesion severity, length and reference diameter was performed and reported on the CARDIOREPORTTM database by a single operator who proposed an initial therapeutic strategy. All lesions were classified according to the ACC/AHA consensus [20]. All ICL, defined by a diameter stenosis of $30 \%$ to $50 \%$ for the left main coronary artery (LMCA) and $40 \%$ to $70 \%$ for nonLMCA lesions, were revaluated on a heart team staff, and IVUS evaluation was decided each time that there was no unanimity on the therapeutic strategy.

\section{Results}

Table 1: Baseline characteristics, coronary angiography and intravascular ultrasound findings.

Table 1: Baseline characteristics, coronary angiography and intravascular ultrasound findings.
\begin{tabular}{|l|c|c|}
\hline \multicolumn{2}{|c|}{ Clinical } & $59,5 \pm 12$ \\
\hline \multicolumn{2}{|c|}{ Age (years) } & $89(78.8)$ \\
\hline \multicolumn{2}{|c|}{ Male gender, n (\%) } & $11(9.7)$ \\
\hline \multirow{2}{*}{ Clinical presentation, $n$ (\%) } & Atypical chest pain & $7(6.2)$ \\
\cline { 2 - 4 } & Silent Ischemia & $27(23.9)$ \\
\cline { 2 - 4 } & Stable Angina & \\
\hline
\end{tabular}

IVUS analysis: Intravascular ultrasound guidance was performed using conventional 6-F guiding catheters and a 0.014$\mathrm{mm}$ guide wire positioned distally, and $40 \mathrm{MHz}$ IVUS catheters (Boston Scientific $®$ ) pulled back automatically at a constant speed of $0.5 \mathrm{~mm} / \mathrm{s}$. After imaging acquisition the lumen-intima and media-adventitia interfaces were measured at the target site following the guidelines of the American College of Cardiology [21]:
a. Minimal lumen area (MLA);
b. plaque burden (PB);
c. lesion length (LL); and
d. Reference diameter (RD).

MLA cut-offs value to perform revascularization were $6 \mathrm{~mm}^{2}$

Clinical Data, Definitions, and Outcomes: Hospital records of all patients were reviewed to obtain information on clinical demographics and medical history. Follow-up information was obtained through review of hospital charts or telephone interviews. The primary outcome was defined as a composite of major adverse cardiac events (MACE), including death, myocardial infarction (MI), and target lesion revascularization (TLR) at 12 months. Death was defined as cardiac mortality. The diagnosis of myocardial infarction was based on either the development of new pathological $\mathrm{Q}$ waves in $\geq 2$ contiguous electrocardiogram leads and/or cardiac enzyme level elevation 3 times the upper limit of normal value. TLR included target lesion percutaneous coronary intervention (PCI) and bypass surgery of the target lesion (CABG).

Statistical analysis: Statistical analysis was performed using IBM $®$ SPSS $®$ Statistics version 20 for Windows. Data are expressed as mean \pm SD for continuous variables and as percentages for discrete variables. The normal distribution of variables was verified by the Kolmogorov-Smirnov test for normality. Categorical data were compared using chi-square test. Event-free survival curves were established using the Kaplan-Meier estimation. All calculated p values were 2-sided and differences were considered to be statistically significant for the LMCA and $4 \mathrm{~mm}^{2}$ for non-LMCA lesions. when the respective $\mathrm{p}$ values were $<0.05$. 
Journal of Cardiology \& Cardiovascular Therapy

\begin{tabular}{|c|c|c|}
\hline & Instable Angina & $34(30.1)$ \\
\hline & NSTEMI & $16(14.2)$ \\
\hline & STEMI & $18(15.9)$ \\
\hline \multirow[t]{2}{*}{ Diabetes mellitus, n (\%) } & \multirow{2}{*}{ Insulin } & $53(46.9)$ \\
\hline & & $14(12.4)$ \\
\hline \multicolumn{2}{|c|}{ Smoking, n (\%) } & $63(55.8)$ \\
\hline \multicolumn{2}{|c|}{ Hypertension, n (\%) } & $63(55.8)$ \\
\hline \multicolumn{2}{|c|}{ Hypercholesterolemia, n (\%) } & $42(37.2)$ \\
\hline \multicolumn{2}{|c|}{ Obesity, n (\%) } & $28(24.8)$ \\
\hline \multicolumn{2}{|c|}{$\geq 3$ CV Risk factor, n (\%) } & $44(38.9)$ \\
\hline \multirow[t]{2}{*}{ CKD, n (\%) } & \multirow{2}{*}{ Haemodialysis } & $10(8.8)$ \\
\hline & & $2(1.7)$ \\
\hline \multicolumn{2}{|c|}{ Prior MI, n (\%) } & $14(12.4)$ \\
\hline \multicolumn{2}{|c|}{ Prior PCI, n (\%) } & $30(26.5)$ \\
\hline \multicolumn{2}{|c|}{ Prior CABG, n (\%) } & $7(6.2)$ \\
\hline \multirow[t]{2}{*}{ Ejection fraction $<55 \%, \mathrm{n}(\%)$} & \multirow{2}{*}{ Ejection fraction $<30 \%$} & $43(38)$ \\
\hline & & $4(3.5)$ \\
\hline \multicolumn{2}{|c|}{ Total Cholesterol, (mmol/L) } & $4.43 \pm 2.62$ \\
\hline \multicolumn{2}{|c|}{ LDL-C, $(\mathrm{mmol} / \mathrm{L})$} & $2.26 \pm 1.56$ \\
\hline \multicolumn{2}{|c|}{ HDL-C, (mmol/L) } & $0.96 \pm 0.56$ \\
\hline \multicolumn{2}{|c|}{ Troponin, $(\mu \mathrm{g} / \mathrm{L})$} & $2.62 \pm 4.21$ \\
\hline \multicolumn{2}{|c|}{ HbA1C, (\%) } & $7.49 \pm 2.33$ \\
\hline \multicolumn{2}{|c|}{ Creatinine clearance, $(\mathrm{mL} / \mathrm{mn})$} & $78.14 \pm 26.54$ \\
\hline \multicolumn{2}{|c|}{ hs-CRP, (mg/dL) } & $0.19 \pm 3.6$ \\
\hline \multirow[t]{2}{*}{ Number of target lesion per procedure, $n(\%)$} & 1 & $64(56.6)$ \\
\hline & $\geq 2$ & $49(43.4)$ \\
\hline \multicolumn{3}{|c|}{ Angiographic finding } \\
\hline \multirow{4}{*}{ Target vessel, n (\%) } & LMCA & $36(24.6)$ \\
\hline & LAD & $118(80.8)$ \\
\hline & LCx & $11(7.5)$ \\
\hline & RCA & $13(8.9)$ \\
\hline \multicolumn{2}{|c|}{ Multi vessel disease, n (\%) } & $74(65.5)$ \\
\hline Lesion type, n (\%) & $\mathrm{A} / \mathrm{B} 1$ & $117(65.7)$ \\
\hline
\end{tabular}




\begin{tabular}{|c|c|c|}
\hline & $\mathrm{B} 2 / \mathrm{C}$ & $61(34.3)$ \\
\hline \multirow{3}{*}{ Estimated lesion length, n (\%) } & $<10 \mathrm{~mm}$ & $50(28.1)$ \\
\hline & 10 to $20 \mathrm{~mm}$ & $112(62.9)$ \\
\hline & $>20 \mathrm{~mm}$ & $16(9)$ \\
\hline \multirow{3}{*}{ Estimated reference diameter, $\mathrm{n}(\%)$} & $>3.5 \mathrm{~mm}$ & $32(18)$ \\
\hline & 3 to $3.5 \mathrm{~mm}$ & $62(34.8)$ \\
\hline & 2.5 to $3 \mathrm{~mm}$ & $84(47.2)$ \\
\hline \multirow{3}{*}{ Estimated lesion severity, n (\%) } & $<30 \%$ & $25(14.1)$ \\
\hline & 30 to $50 \%$ & $67(37.6)$ \\
\hline & 50 to $70 \%$ & $86(48.3)$ \\
\hline \multicolumn{3}{|c|}{ IVUS finding } \\
\hline \multirow{2}{*}{$\operatorname{MLA}\left(\mathrm{mm}^{2}\right)$} & LMCA & $8.18 \pm 3.81$ \\
\hline & Non-LMCA & $5.01 \pm 2.23$ \\
\hline \multirow{2}{*}{ PB (\%) } & LMCA & $53.11 \pm 13.19$ \\
\hline & Non-LMCA & $61.56 \pm 10.81$ \\
\hline \multirow{2}{*}{$\operatorname{LL}(\mathrm{mm})$} & LMCA & $4.11 \pm 1.54$ \\
\hline & Non-LMCA & $15.08 \pm 4.18$ \\
\hline \multirow[t]{2}{*}{ Mean RD (mm) } & LMCA & $4.57 \pm 0.86$ \\
\hline & Non-LMCA & $3.08 \pm 0.28$ \\
\hline
\end{tabular}

A total of 113 consecutive patients were included, 146 arteries and 178 lesions were analysed. Baseline clinical characteristics, angiographic and IVUS finding are summarized in (Table 1). Complete follow-up data were available for 112 patients over a mean follow-up time of $20 \pm 10$ months. There was no protocol violation and all patients with MLA values below the defined cutoffs underwent either PCI or CABG. Overall revascularization was deferred for 46 patients (40.7\%) after IVUS assessment. There were significantly more patients with diabetes mellitus, hypercholesterolemia and complex lesions in the revascularized group (Table 2).

Table 2: Clinical and angiographic characteristics.

\begin{tabular}{|c|c|c|c|}
\hline & Revascularized groupe & Deferred groupe & 0.304 \\
\hline Age (years) & $60.1 \pm 9.9$ & $58.6 \pm 14.5$ & 0.719 \\
\hline Male gender (\%) & 77.6 & 80.4 & 0.022 \\
\hline Diabetes millitus (\%) & 55.2 & 34.8 & 0.364 \\
\hline Smoking (\%) & 52.2 & 60.9 & 0.526 \\
\hline Hypertension (\%) & 58.8 & 52.2 & 0.016 \\
\hline Hypercholesterolemia (\%) & 46.3 & 23.9 & 0.051 \\
\hline Obesity (\%) & 31.3 & 15.2 & 0.470 \\
\hline CKD (\%) & 10.4 & 6.5 & 0.142 \\
\hline Prior CABG (\%) & 9 & 2.2 & 0.406 \\
\hline Prior MI (\%) & 16.4 & 10.9 & 0.700 \\
\hline
\end{tabular}




\section{Journal of Cardiology \& Cardiovascular Therapy}

\begin{tabular}{|c|c|c|c|}
\hline Multivessel desease (\%) & 65.7 & 65.2 & 0.960 \\
\hline LMCA lesion (\%) & 26.9 & 39.1 & 0.169 \\
\hline Lesion type B2/C (\%) & 49 & 17.5 & $<0.001$ \\
\hline
\end{tabular}

Decision making: $31 \%$ of the LMCA lesions and $41 \%$ of the non-LMCA lesions that were angiographycally estimated more than $50 \%$ stenosis were not significant as assessed by IVUS $(\mathrm{p}<0.01)$. This discordance resulted in a change in the therapeutic strategy in 49 patients $(43.3 \%)$ with a significant reduction in the indications of revascularization: $81.6 \%$ of the initial PCI or CABG indications in this group were delayed. This was significantly more frequent with lesions involving the LMCA and the proximal left anterior descending artery or when there were 2 or more intermediate lesions to evaluate (Figures 1-4).

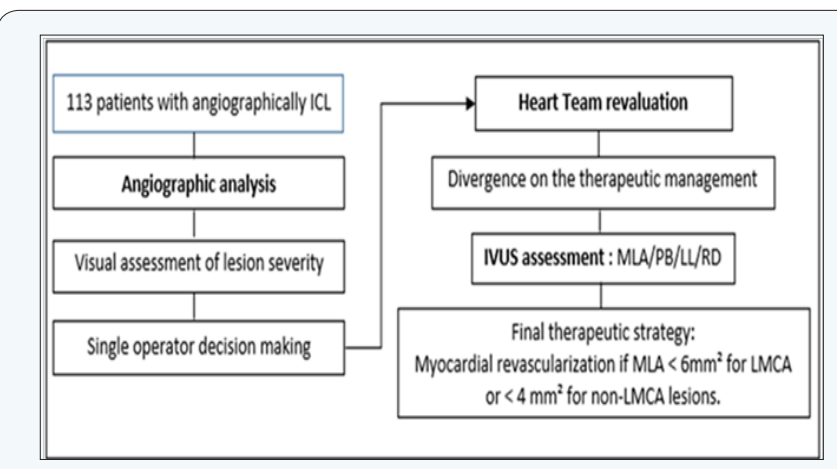

Figure 1: Study design.

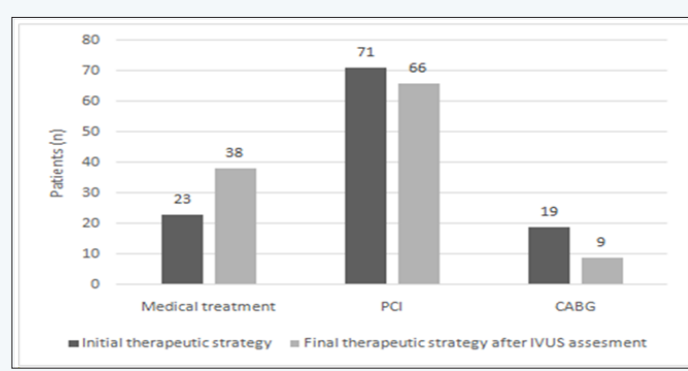

Figure 2: Changes in therapeutic strategy after IVUS assessment: Using IVUS assessment of ICL led to a decreased revascularisation procedures number when compared with initial planned strategy based on the visual assessment of the angiogram. PCl: Percutaneous coronary intervention; CABG: Coronary artery bypass graft.

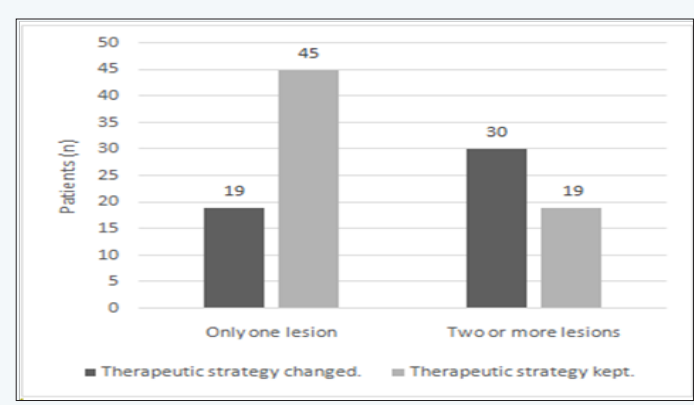

Figure 3: Impact of the number of target lesions on the change of therapeutic strategies: There was significantly more changes on therapeutic strategy each time that IVUS assessment was performed on two or more intermediate coronary lesions (ICL) when compared with patient with a single ICL.

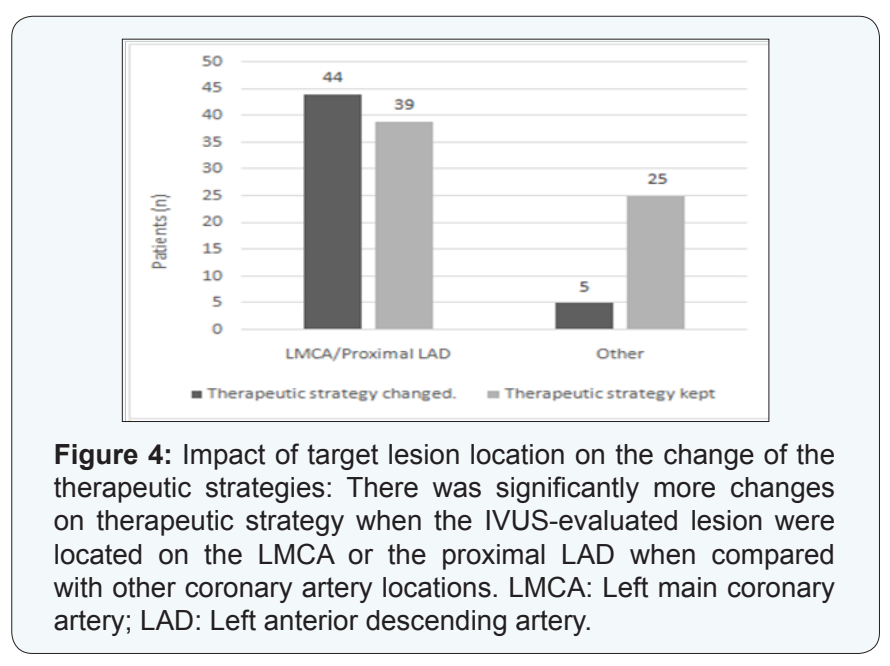

Major adverse cardiovascular event at 12 months followup: Overall, 12 patients presented a major cardiac event after a mean follow-up of $20 \pm 10$ months. In the deferred group, only one cardiac death was reported and one patient presented a MI for which he underwent PCI. There were two cardiac deaths. One patient died after complications of bypass surgery and the second from a NSTEMI complicated by cardiogenic shock, after proximal LAD PCI was not performed in basis of IVUS finding.

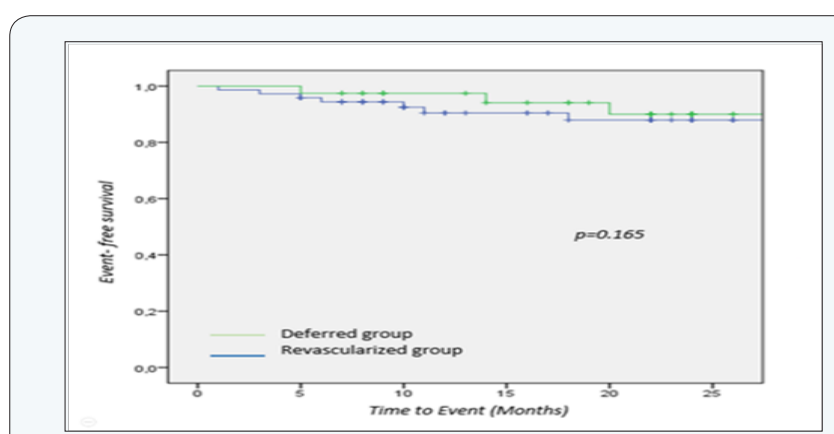

Figure 5: Kaplan-Meier event free survival curves for the composite endpoint: No significant difference was observed in term of cardiac death, target lesion myocardial infarction or target lesion revascularisation between the deferred and the revascularized group.

Three MI occurred: two patients had NSTEMI related to late stent thrombosis, and one patient had anterior STEMI one month after he underwent IVUS assessment for an ICL in the proximal LAD (MLA $=8.61 \mathrm{~mm}^{2}$ ). During the 12-month follow up period, 10 TLR were performed. Nine patients had PCI; eight with DES and one with BMS. Only one patient had CABG. We observed no 
significant differences between the revascularized patients and the patients whose revascularization was postponed in terms of mortality (1.5\% and $2.2 \%$ respectively, p=0.7), 12-month rate of MACE $(10.6 \%$ and $2.2 \%, \mathrm{p}=0.165)$, myocardial infarction $(4.5 \%$ and $2.2 \%, \mathrm{p}=0.44)$ and 12 -month rate of target lesion revascularization $(10.7 \%$ and $2.2 \%, p=0.23$ ) (Figures $5 \& 6$ ).

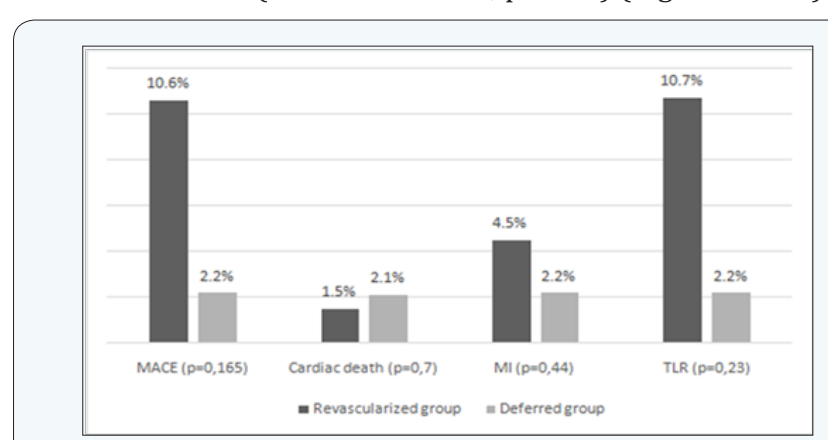

Figure 6: Clinical outcomes at 12 months: Deferring coronary revascularisation of intermediate coronary lesion based on IVUS MLA was correlated with favourable outcomes without significant difference compared to the revascularized group. MACE: Major adverse cardiovascular event; MI: Myocardial infarction; TLR: Target lesion revascularization.

No cardiac events occurred during the first 12 months follow up for all the patients with LMCA ICL in whom revascularization was deferred. Age and diabetes mellitus were the only significant univariate predictors of, respectively, cardiac death $(\mathrm{p}<0.01)$ and TLR ( $p=0.015)$. The change of the therapeutic strategy after IVUS evaluation was not correlated with significant change in events rates (Table 3).

Table 3: Predictors of clinical events.

\begin{tabular}{|c|c|c|c|c|}
\hline & MACE & $\begin{array}{c}\text { Cardiac } \\
\text { death }\end{array}$ & MI & TLR \\
\hline $\begin{array}{c}\text { Age }>70 \\
\text { years }\end{array}$ & 0.89 & $<0.01$ & 0.77 & 0.141 \\
\hline $\begin{array}{c}\text { Diabetes } \\
\text { millitus }\end{array}$ & 0.51 & 0.51 & 0.28 & 0.015 \\
\hline $\begin{array}{c}\text { CV risk } \\
\text { factors > } 2\end{array}$ & 0.36 & 0.62 & 0.13 & 0.098 \\
\hline $\begin{array}{c}\text { Multi vessel } \\
\text { disease }\end{array}$ & 0.54 & 0.21 & 0.25 & 0.086 \\
\hline $\begin{array}{c}\text { Ejection } \\
\text { fraction }< \\
35 \%\end{array}$ & 0.77 & 0.71 & 0.83 & 0.256 \\
\hline $\begin{array}{c}\text { Change of } \\
\text { therapeutic } \\
\text { strategy } \\
\text { after IVUS }\end{array}$ & 0.33 & 0.7 & 0.44 & 0.599 \\
\hline
\end{tabular}

\section{Discussion}

The present study showed the following:

a. There was a poor correlation between visual angiographic estimation and IVUS MLA assessment of a coronary stenosis severity, b. This led to a change of therapeutic strategy in $43.3 \%$ of cases,

c. The use of a MLA cut-off value of $4 \mathrm{~mm}^{2}$ for the non-LMCA stenosis and $6 \mathrm{~mm}^{2}$ for the LMCA stenosis, was correlated with favourable outcomes.

The limitations of coronary angiography in assessing ICL severity have been well documented. The inter-observer variability is high and little further information is gleaned from computer-assisted quantitative angiography [1,22-24]. IVUS has been used since the 1990's to assess the severity of intermediate coronary stenosis and several studies proved the good correlation between MLA and the physiological significance of such lesions. Its incremental diagnostic value was proven repeatedly for the most challenging lesions, those of the left main (LM). Sano et al. [25] reported three times more significant lesions by IVUS among 115 consecutive patients with a de novo, angiographically ambiguous, intermediate LM lesions, compared to QCA [25].

The cut-off value for lumen area to predict ischemia is still disputed, and range from 2.1 to $4.4 \mathrm{~mm}^{2}$ [2-16,26] for the nonLMCA lesions and 4.8 to $7.5 \mathrm{~mm}^{2}$ [27-30] for the LMCA lesions. In 53 non LMCA intermediate lesions, Briguori et al [16] reported that an MLA cut off of $4 \mathrm{~mm}^{2}$ was the best IVUS parameter correlated with identifying FFR $<0.75$ with $92 \%$ sensitivity and $56 \%$ specificity. However, recent studies have found lower MLA cut off values and have used a combination of other IVUS parameters to predict FFR. In a multicenter, prospective, international registry of 350 patients with 367 intermediate coronary lesions (FIRST: Fractional Flow Reserve and Intravascular Ultrasound Relationship Study) [12], Walksman et al. reported that an MLA < 3,07 $\mathrm{mm}^{2}$ (64.0\% sensitivity, $64.9 \%$ specificity, area under curve $[\mathrm{AUC}]=0.65$ ) was the best threshold value for identifying FFR $<0.8$. Same results were founded by Ben Dor et al. [8] with improved accuracy when reference vessel-specific analyses were performed. Trials conducted in East Asia population have reported even lower MLA cut off, Kang et al. [26] established that the best cut off value of the MLA to predict FFR $<0.80$ was $<2.4 \mathrm{~mm}^{2}$, with a diagnostic accuracy of $68 \%$ (90\% sensitivity, $60 \%$ specificity).

Few studies compared IVUS finding with FFR as the "gold standard" for determining the functional significance of LMCA ICL. In an analysis of 55 western patients, Jasti et al. [27] reported that an MLA $<6 \mathrm{~mm} 2$ strongly predicted FFR $<0.8$ (sensitivity and specificity of $93 \%$ and $95 \%$, respectively). Lower MLA cutoff was again reported in Asian population; Kang et al. suggested that $4,8 \mathrm{~mm}^{2}$ was the best MLA cutoff correlated to an FFR $<0,8$ with $89 \%$ sensitivity and $83 \%$ specificity.

Care must be taken in the interpretation of these studies conducted in different populations, many in Japan and Korea where there is a large usage of IVUS in the cat lab. There is presently no IVUS report from North Africa / Arabic countries 
characterized by a higher incidence of smoking, diabetes mellitus, and hypertension.

Different studies had reported that using IVUS to guide decision making induced a significant change in the therapeutic strategy. Mintz et al. [31] reported that pre intervention IVUS imaging performed in 301 patients led to a change on revascularisation therapy in 121 patients (40\%). A higher rate of change in clinical decision after IVUS assessment was reported by other authors (60 to $70,6 \%$ ) [32-34]. However there is few clinical trials that established the clinical safety of using IVUS MLA to defer a myocardial revascularization. The chosen MLA cut-off thresholds to defer revascularization in those studies were $4 \mathrm{~mm}^{2}$ for the non-LMCA ICL [35-37] and $6 \mathrm{~mm}^{2}[28,38]$ or $7.5 \mathrm{~mm}^{2}$ [29] for the LMCA ICL (Table 4).

Table 4: Clinical outcomes after using IVUS MLA to defer myocardial revascularisation.

\begin{tabular}{|c|c|c|c|c|c|}
\hline & $\begin{array}{c}\text { ICL } \\
\text { location }\end{array}$ & $\begin{array}{c}\text { Patients } \\
\text { (n) }\end{array}$ & $\begin{array}{c}\text { MLA } \\
\text { cut-off }\end{array}$ & $\begin{array}{c}\text { Follow- } \\
\text { up }\end{array}$ & $\begin{array}{c}\text { MACE } \\
\text { rate } \\
\text { (\%) }\end{array}$ \\
\hline $\begin{array}{c}\text { Abizaid 1999 } \\
(35)\end{array}$ & $\begin{array}{c}\text { Non- } \\
\text { LMCA }\end{array}$ & 300 & $4 \mathrm{~mm}^{2}$ & $\begin{array}{c}12 \\
\text { months }\end{array}$ & $8 \%$ \\
\hline $\begin{array}{c}\text { Nam 2010 } \\
(36)\end{array}$ & $\begin{array}{c}\text { Non- } \\
\text { LMCA }\end{array}$ & 167 & $4 \mathrm{~mm}^{2}$ & $\begin{array}{c}12 \\
\text { months }\end{array}$ & $3.2 \%$ \\
\hline $\begin{array}{c}\text { Hernandez* } \\
\text { 2013 (37) }\end{array}$ & $\begin{array}{c}\text { Non- } \\
\text { LMCA }\end{array}$ & 400 & $4 \mathrm{~mm}^{2}$ & $\begin{array}{c}24 \\
\text { months }\end{array}$ & $6.4 \%$ \\
\hline $\begin{array}{c}\text { Abizaid 1999 } \\
(38)\end{array}$ & LMCA & 122 & $6 \mathrm{~mm}^{2}$ & $\begin{array}{c}12 \\
\text { months }\end{array}$ & $14 \%$ \\
\hline $\begin{array}{c}\text { Fassa 2005 } \\
(29)\end{array}$ & LMCA & 214 & $7.5 \mathrm{~mm}^{2}$ & 5 years & $11.6 \%$ \\
\hline $\begin{array}{c}\text { LITR0 2011 } \\
(28)\end{array}$ & LMCA & 354 & $6 \mathrm{~mm}^{2}$ & 24 mois & $12.7 \%$ \\
\hline
\end{tabular}

In 300 patients with non LMCA ICL, deferring PCI on the basis of an IVUS MLA $\geq 4.0 \mathrm{~mm} 2$ was associated with a low rate of events ( $8 \%$ at 12 months) [35]. Clinical safety of this MLA cut off was confirmed by others studies showing even fewer cardiac events [36,37]. Otherwise, compare to FFR based decision making, Hernandez et al. [37] reported that even if IVUS assessment led to more revascularization procedures, there was no significant differences in MACE-free survival $(97.7 \%$ at one year and $93.1 \%$ at two years in the FFR group and $97.7 \%$ at one year and $95.6 \%$ at two years in the IVUS group; $\mathrm{p}=0.35$ ) and among those with deferred intervention $(97.9 \%$ at one year and $94.2 \%$ at two years in the FFR group and $96.5 \%$ at one year and $93.6 \%$ at two years in the IVUS group; $\mathrm{p}=0.7$ ).

For the LMCA ICL, different studies reported that using the IVUS MLA to defer myocardial revascularisation is also correlated with favourable outcomes [28,29,38]. In the LITRO study [28], which enrolled 354 patients with LMCA ICL, there was no significant difference between the deferred and revascularized groups in terms of cardiac death-free survival $(97.7 \%$ vs $94.5 \%$, respectively, $\mathrm{P}=0.5)$ and event-free survival $(87.3 \%$ vs $80.6 \%$, respectively, $\mathrm{P}=0.3$ ) after a mean follow up of 24 months. Our study confirmed the high negative predictive value of this MLA cut-off and accordingly the clinical safety of delaying myocardial revascularization of ICL based on IVUS evaluation.

Study limitations: Principal's limitations of the present study are:

a. The limited number of included patients due to economic difficulties in an emergent region where IVUS prone are not reimbursed by any insurance funds. We estimate that only one in four patients with ICL underwent IVUS analysis.

b. The MLA cut off value of $4 \mathrm{~mm}^{2}$ chose to perform revascularisation on non-LMCA lesions might to appear too high (and well above the ischemic threshold) [12], and

c. The lack of clear criteria to make the initial therapeutic decision which was at the operator's discretion.

\section{Conclusion}

The use of IVUS in a population from Maghreb to assess angiographically intermediate coronary lesions is correlated with a significant decrease of myocardial revascularization indications and favourable long term outcomes.

\section{Compliance with Ethical Standards}

Conflict of Interest: The authors declare that they have no conflict of interest.

Ethical approval: All procedures performed involving human participants were in accordance with the ethical standards of the national research committee. There were no animal study.

Informed consent: Informed consent was obtained from all individual participants included in this study.

\section{References}

1. Topol EJ, Nissen SE (1995) Our Preoccupation with Coronary Luminology the Dissociation Between Clinical and Angiographic Findings in Ischemic Heart Disease. Circulation 92(8): 2333-2342.

2. Abizaid A, Mintz GS, Pichard AD, Kent KM, Satler LF, et al. (1998) Clinical, intravascular ultrasound, and quantitative angiographic determinants of the coronary flow reserve before and after percutaneous transluminal coronary angioplasty. Am J Cardiol 82(4): 423-428.

3. Lee CH, Tai BC, Soon CY, Low AF, Poh KK, et al. (2010) New set of intravascular ultrasound-derived anatomic criteria for defining functionally significant stenoses in small coronary arteries (results from Intravascular Ultrasound Diagnostic Evaluation of Atherosclerosis in Singapore [IDEAS] study). Am J Cardiol 105(10): 1378-1384.

4. Takagi A, Tsurumi Y, Ishii Y, Suzuki K, Kawana M, et al. (1999) Clinical potential of intravascular ultrasound for physiological assessment of coronary stenosis: relationship between quantitative ultrasound tomography and pressure-derived fractional flow reserve. Circulation 100(3): 250-255.

5. Kang SJ, Ahn JM, Song H, Kim WJ, Lee JY, et al. (2012) Usefulness of minimal luminal coronary area determined by intravascular ultrasound to predict functional significance in stable and unstable angina pectoris. Am J Cardiol 109(7): 947-953. 
6. Ahn JM, Kang SJ, Mintz GS, Oh JH, Kim WJ, et al. (2011) Validation of minimal luminal area measured by intravascular ultrasound for assessment of functionally significant coronary stenosis comparison with myocardial perfusion imaging. JACC Cardiovasc Interv 4(6): 665671

7. Ben-Dor I, Torguson R, Gaglia MA, Gonzalez MA, Maluenda G, et al. (2011) Correlation between fractional flow reserve and intravascular ultrasound lumen area in intermediate coronary artery stenosis. EuroIntervention 7(2): 225-233.

8. Ben Dor I, Torguson R, Deksissa T, Bui AB, Xue Z, et al. (2012) Intravascular ultrasound lumen area parameters for assessment of physiological ischemia by fractional flow reserve in intermediate coronary artery stenosis. Cardiovasc Revascularization Med Mol Interv 13(3): 177-182.

9. Koo BK, Yang HM, Doh JH, Choe H, Lee SY, et al. (2011) Optimal Intravascular Ultrasound Criteria and Their Accuracy for Defining the Functional Significance of Intermediate Coronary Stenoses of Different Locations. JACC Cardiovasc Interv 4(7): 803-811.

10. Koh JS, Koo BK, Kim JH, Yang HM, Park KW, et al. (2012) Relationship between fractional flow reserve and angiographic and intravascular ultrasound parameters in ostial lesions: major epicardial vessel versus side branch ostial lesions. JACC Cardiovasc Interv 5(4): 409-415.

11. Chen SL, Xu B, Chen JB, Xu T, Ye F, et al. (2013) Diagnostic accuracy of quantitative angiographic and intravascular ultrasound parameters predicting the functional significance of single de novo lesions. Int Cardiol 168(2): 1364-1369.

12. Waksman R, Legutko J, Singh J, Orlando Q, Marso S, et al. (2013) FIRST: Fractional Flow Reserve and Intravascular Ultrasound Relationship Study. J Am Coll Cardiol 61(9): 917-923.

13. Yang HM, Tahk SJ, Lim HS, Yoon MH, Choi SY, et al. (2014) Relationship between intravascular ultrasound parameters and fractional flow reserve in intermediate coronary artery stenosis of left anterior descending artery: intravascular ultrasound volumetric analysis Catheter Cardiovasc Interv 83(3): 386-394.

14. Kang SJ, Ahn JM, Han S, Lee JY, Kim WJ, et al. (2013) Sex differences in the visual-functional mismatch between coronary angiography and intravascular ultrasound versus fractional flow reserve. JACC Cardiovasc Interv 6(6): 562-568.

15. Nishioka T, Amanullah AM, Luo H, Berglund H, Kim CJ, et al. (1999) Clinical validation of intravascular ultrasound imaging for assessment of coronary stenosis severity: comparison with stress myocardial perfusion imaging. J Am Coll Cardiol 33(7): 1870-1878.

16. Briguori C, Anzuini A, Airoldi F, Gimelli G, Nishida T, et al. (2001) Intravascular ultrasound criteria for the assessment of the functional significance of intermediate coronary artery stenoses and comparison with fractional flow reserve. Am J Cardiol 87(2):136-141.

17. Stone GW, Maehara A, Lansky AJ, de Bruyne B, Cristea E, et al. (2011) A Prospective Natural-History Study of Coronary Atherosclerosis. N Engl J Med 364(3): 226-235.

18. Ben Romdhane H, Ali SB, Aissi W, Traissac P, Aounallah-Skhiri H, et al. (2014) Prevalence of diabetes in Northern African countries: the case of Tunisia. BMC Public Health 14: 86

19. Nejjari C, Arharbi M, Chentir MT, Boujnah R, Kemmou O, et al. (2013) Epidemiological Trial of Hypertension in North Africa (ETHNA): an international multicentre study in Algeria, Morocco and Tunisia. J Hypertens 31(1): 49-62.

20. Stone GW, Reifart NJ, Moussa I, Hoye A, Cox DA, et al. (2005) Percutaneous Recanalization of Chronically Occluded Coronary Arteries A Consensus Document: Part II. Circulation 112: 2530-2537.

21. Mintz GS, Nissen SE, Anderson WD, Bailey SR, Erbel R, et al. (2001) American College of Cardiology Clinical Expert Consensus Document on Standards for Acquisition, Measurement and Reporting of Intravascular Ultrasound Studies (IVUS). A report of the American College of Cardiology Task Force on Clinical Expert Consensus Documents. J Am Coll Cardiol 37(5): 1478-1492.

22. Fischer JJ, Samady H, McPherson JA, Sarembock IJ, Powers ER, et al. (2002) Comparison between visual assessment and quantitative angiography versus fractional flow reserve for native coronary narrowings of moderate severity. Am J Cardiol 90(3): 210-215.

23.Zir LM, Miller SW, Dinsmore RE, Gilbert JP, Harthorne JW (1976) Interobserver variability in coronary angiography. Circulation 53: 627632.

24. Tobis J, Azarbal B, Slavin L (2007) Assessment of Intermediate Severity Coronary Lesions in the Catheterization Laboratory. J Am Coll Cardiol 49(8): 839-848.

25. Sano K, Mintz GS, Carlier SG, de Ribamar Costa J, Qian J, et al. (2007) Assessing intermediate left main coronary lesions using intravascular ultrasound. Am Heart J 154(5): 983-988.

26. Kang SJ, Lee JY, Ahn JM, Mintz GS, Kim WJ, et al. (2011) Validation of intravascular ultrasound-derived parameters with fractional flow reserve for assessment of coronary stenosis severity. Circ Cardiovasc Interv 4(1): 65-71.

27. Jasti V, Ivan E, Yalamanchili V, Wongpraparut N, Leesar MA (2004) Correlations Between Fractional Flow Reserve and Intravascular Ultrasound in Patients With an Ambiguous Left Main Coronary Artery Stenosis. Circulation 110(18): 2831-2836.

28. de la Torre Hernandez JM, Hernández Hernandez F, Alfonso F, Rumoroso JR, Lopez-Palop R, et al. (2011) Prospective Application of Pre-Defined Intravascular Ultrasound Criteria for Assessment of Intermediate Left Main Coronary Artery Lesions. J Am Coll Cardiol 58(4): 351-358.

29. Fassa A, Wagatsuma K, Higano S, Mathew V, Barsness G, et al. (2005) Intravascular ultrasound-guided treatment for angiographically indeterminate left main coronary artery disease A long-term follow-up study. J Am Coll Cardiol 45(2): 204-211.

30. Kang SJ, Lee JY, Ahn JM, Song HG, Kim WJ, et al. (2011) Intravascular Ultrasound-Derived Predictors for Fractional Flow Reserve in Intermediate Left Main Disease. JACC Cardiovasc Interv 4(11): 11681174

31. Mintz GS, Pichard AD, Kovach JA, Kent KM, Satler LF, et al. (1994) Impact of preintervention intravascular ultrasound imaging on transcatheter treatment strategies in coronary artery disease. Am J Cardiol 73(7): 423-430.

32. Lee DY, Eigler N, Luo H, Nishioka T, Tabak SW, et al. (1995) Effect of intracoronary ultrasound imaging on clinical decision making. Am Heart J 129(6): 1084-1093.

33. Bruchhäuser J, Sechtem U, Höpp HW, Erdmann E (1997) Intracoronary ultrasound changes the therapeutic approach in ambivalent angiography findings. Z Kardiol 86(2): 138-147.

34. Wolfhard U, Görge G, Konorza T, Haude M, Ge J, et al. (1998) Intravascular ultrasound (IVUS) examination reverses therapeutic decision from percutaneous intervention to a surgical approach in patients with alterations of the left main stem. Thorac Cardiovasc Surg 46(5): 281-284.

35. Abizaid AS, Mintz GS, Mehran R, Abizaid A, Lansky AJ, et al. (1999) Long-Term Follow-Up After Percutaneous Transluminal Coronary Angioplasty Was Not Performed Based on Intravascular Ultrasound Findings : Importance of Lumen Dimensions. Circulation 100(3): 256261.

36. Nam CW, Yoon HJ, Cho YK, Park HS, Kim H, et al. (2010) Outcomes of Percutaneous Coronary Intervention in Intermediate Coronary Artery Disease. JACC Cardiovasc Interv 3(8): 812-817. 
37. de la Torre Hernandez JM, Lopez-Palop R, Garcia Camarero T, Carrillo Saez P, Martin Gorria G, et al. (2013) Clinical outcomes after intravascular ultrasound and fractional flow reserve assessment of intermediate coronary lesions. Propensity score matching of large cohorts from two institutions with a differential approach. EuroIntervention 9(7): 824-830.
38. Abizaid AS, Mintz GS, Abizaid A, Mehran R, Lansky AJ, et al. (1999) Oneyear follow-up after intravascular ultrasound assessment of moderate left main coronary artery disease in patients with ambiguous angiograms. J Am Coll Cardiol 34(3): 707-715.

Your next submission with JuniperPublishers will reach you the below assets

- Quality Editorial service

- Swift Peer Review

- Reprints availability

- E-prints Service

- Manuscript Podcast for convenient understanding

- Global attainment for your research

- Manuscript accessibility in different formats ( Pdf, E-pub, Full Text, audio)

- Unceasing customer service

Track the below URL for one-step submission https://juniperpublishers.com/online-submission.php 